\title{
Sieve mesh-size and taxonomic resolution needed to describe natural spatial variation of marine macrofauna
}

\author{
R. J. James ${ }^{1, *}$, M. P. Lincoln Smith', P. G. Fairweather ${ }^{2, * *}$ \\ ${ }^{1}$ The Ecology Lab Pty Ltd, 14/28-34 Roseberry Street, Balgowlah, New South Wales 2093, Australia \\ ${ }^{2}$ Graduate School of the Environment, Macquarie University, New South Wales 2109, Australia
}

\begin{abstract}
The effects of sieve mesh-size and taxonomic resolution on patterns of natural spatial variation of soft-sediment, marine macrofauna were examined simultaneously over a range of depths and 2 spatial scales. Previous studies have considered the effects of mesh-size and taxonomic resolution separately, mainly for macrofauna exposed to pollution. Mesh-size $(0.5 \mathrm{~mm}$ or $1 \mathrm{~mm})$ and taxonomic resolution (species or family) made little difference to the spatial patterns detected by non-parametric, multivariate analyses (MDS and ANOSIM) for assemblages of macrofauna but results suggested that slightly more information was lost by using the coarser mesh than by using the coarser level of taxonomic resolution. For about half of the populations of individual taxa examined using parametric, univariate analyses, mesh-size affected the interpretation of spatial patterns to some degree. The absolute abundances of some other populations of macrofauna were underestimated using a $1 \mathrm{~mm}$ mesh as compared to a $0.5 \mathrm{~mm}$ mesh but patterns of spatial variation of these families did not vary between meshsizes. There were often less than 5 species per family and the spatial variation of the single most abundant species in each family probably dominated the spatial patterns detected in family-level analyses. For some speciose families (e.g. Spionidae, Corophiidae), however, the spatial variation of particular, relatively abundant species may differ from that detected at the family level. The best way of incorporating rarer taxa into analyses may be multivariate methods which also seemed more robust to coarser mesh-sizes and levels of taxonomic resolution than univariate methods. Samples of macrofauna sieved through a $0.5 \mathrm{~mm}$ mesh took significantly longer to sort to major groups than $1 \mathrm{~mm}$ samples. The size of this difference, however, depended on the location from which the samples were taken. Since many more samples can be processed per unit time, coarser mesh-sizes and levels of taxonomic resolution should allow greater replication at both large and small scales for macrofauna with little loss of information.
\end{abstract}

KEY WORDS: Assemblages - Australia - Macrofauna Pilot studies - Populations - Sieve mesh-size Taxonomic resolution

\section{INTRODUCTION}

A fundamental step in any ecological investigation is the description of spatial patterns in the abundance of organisms (Andrew \& Mapstone 1987). Generation of hypotheses, the design of experiments and management decisions are often based on information derived from

- Graduate School of the Environment, Macquarie University, New South Wales 2109, Australia

- Division of Water Resources, CSIRO, Private Mail Bag 3. Griffith, New South Wales 2680, Australia these patterns (Andrew \& Mapstone 1987). Pilot studies are advocated to allow the design of cost-effective sampling programmes for subsequent, larger investigations (e.g. Green 1979, Kennelly \& Underwood 1984). Here we detail such a pilot study for a major survey of softsediment macrofauna. This study is unique because it simultaneously examines how varying both the size of mesh used for sieving samples and the level of taxonomic resolution affects interpretations of spatial patterns in natural assemblages of macrofauna. Furthermore, interactions of these 2 factors with a range of water depths and 2 spatial scales of variation are documented 
Sieve mesh-size is usually set at 0.5 or $1 \mathrm{~mm}$ in studies of marine macrofauna (Eleftheriou \& Holme 1984, Kingston \& Riddle 1989). The choice of mesh-size depends on the particular aims of the study (e.g. a study of recruitment or a more general survey; Reish 1959), coarseness of the sediment (which affects the volume of sediment retained and hence processing time) and the desirability or not of collecting juvenile macrofauna (which can be difficult to identify because taxonomic descriptions are usually based on characteristics of adults). The relative accuracy of different mesh-sizes in providing estimates of absolute abundance has been assessed in a few studies (e.g. Reish 1959, Eleftheriou \& Holme 1984, Bishop \& Hartley 1986, Bachelet 1990). Ecologists, however, are usually interested in relative estimates of abundance which are used to identify patterns of spatial and temporal variation. Rees (1984) showed that patterns of temporal variation in the abundance of 2 species of polychaete differed when 0.5 and $1 \mathrm{~mm}$ meshes were used. The effects of mesh-size on the description of spatial variation in multispecies assemblages of macrofauna, however, have not been examined.

The taxonomic level of identification of macrofauna should also depend on the aim of the study (Ellis 1985, Kingston \& Riddle 1989). Recent studies have shown that patterns of spatial variation consistent with anthropogenic disturbances are often similar both for species and broader taxonomic categories of macrofauna (Warwick 1988a, b. Ferraro \& Cole 1990. 1992, Gray et al. 1990, Warwick et al. 1990), meiofauna (e.g. Heip et al. 1988, Herman \& Heip 1988), coral reef fish (Dawson-Shepherd et al. 1992) and the fauna of kelp holdfasts (Smith \& Simpson 1993). Warwick (1988a, b) proposed that anthropogenic disturbances affect assemblages of macrofauna at higher taxonomic levels than natural environmental variation, which affects assemblages at the level of species. This suggests that identification to species is required to adequately describe natural patterns of spatial variation in assemblages of macrofauna. There is, however, a trade-off between the level of identification and the number of samples that can be processed in a given amount of time (e.g. Warwick 1993), and there are problems with actually identifying biota to species in parts of the world without a good taxonomic database, including Australia. Adequate descriptions of spatial variation may require a large number of samples and therefore the effect of taxonomic resolution on the description of natural spatial variation of macrofauna needs to be investigated. Differences between spatial patterns detected at the taxonomic levels of species and family (as intermediate between species and phylum) are examined here.
Many studies of assemblages of macrofauna have used non-parametric, multivariate analyses to interpret the data (Warwick 1988a, b, Gray et al. 1990, Warwick et al. 1990, Clarke 1993). There are good reasons (e.g. see Underwood 1993), however, why populations of individual species should be studied using parametric, univariate analyses (e.g. power of tests, more complex designs, test quantitative null hypotheses). Thus, we examined the effects of sieve mesh-size and taxonomic resolution on the interpretation of spatial patterns for both assemblages and particular populations of macrofauna.

\section{METHODS}

Samples were collected from similar shelf sand bodies (Roy 1984) at 2 locations, Providential Head (PH) and Bass Point (BP) off the east coast of New South Wales, Australia (Fig. 1). These 2 locations are putatively unpolluted. Samples were collected on 11

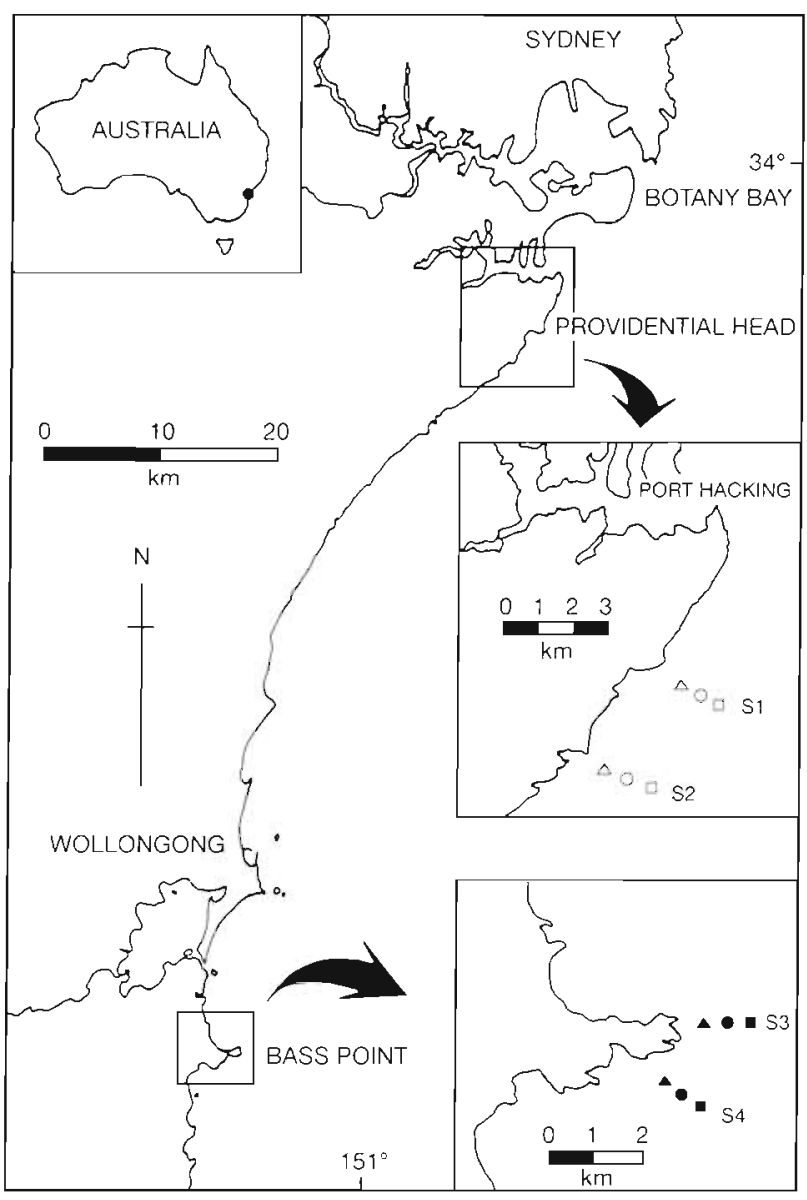

Fig. 1 Locations, sites and depths sampled for macrofauna. Three depths were sampled at the 2 sites within each location: $(2,4) 25$ to $30 \mathrm{~m}_{i}(0, \bullet) 35$ to $40 \mathrm{mi}(\square, \square) 45$ to $50 \mathrm{~m}$ 
and 15 January 1990 at PH and on 1 February 1990 at BP. Sediments were moderately well to well sorted, fine to medium grained quartz sands with variable shell content (but $<15 \%$ ) and $<5 \%$ fine materials $(<75 \mu \mathrm{m})$ (Metromix 1993). Two sites were chosen randomly within each location. The 2 sites within each location were approximately 2 to $3 \mathrm{~km}$ apart and each site extended $<0.5 \mathrm{~km}$ parallel to the shore while the boundaries normal to the shore were determined by depth and were between about 1 and $1.5 \mathrm{~km}$ long (see Fig. 1). At each site, 6 Smith-McIntyre grab samples $\left(0.05 \mathrm{~m}^{2}\right.$ in area) were taken within each of 3 depth ranges: 25 to 30,35 to 40 and 45 to $50 \mathrm{~m}$. The grab penetrated approximately $10 \mathrm{~cm}$ into the sediment. To provide independent estimates of macrofaunal abundance, 3 samples were sieved through a $0.5 \mathrm{~mm}$ mesh and 3 through a $1 \mathrm{~mm}$ mesh. Material retained on the sieves was preserved in $10 \%$ formalin and seawater and later stained with Biebrich Scarlet.

Polychaetes, molluscs, crustaceans and other phyla were sorted with the aid of magnifying lamps (approx. $2 \times$ ). All $0.5 \mathrm{~mm}$ samples were then scanned using a binocular microscope (approx. 12x). The time taken to sort each sample into the above 4 groups was noted and included the time taken to scan $0.5 \mathrm{~mm}$ samples under the binocular microscope.

Analyses of assemblages. Multivariate statistical techniques were used to describe spatial variation in assemblages. Four sets of data corresponding to each combination of mesh-size $(0.5 \mathrm{~mm}$ or $1 \mathrm{~mm})$ and level of identification (family or species) were analysed (36 grab samples for each analysis; $n=3$ replicates from each of 2 locations, 2 sites within each location and 3 depths at each site). One sample of molluscs was lost and abundances for molluscs in this sample were then estimated from the average of the other 2 replicate samples taken from the same site and depth. Meiofauna (e.g. copepods and nematodes) were not included in the analyses.

Analyses of spatial patterns in assemblages followed the procedures in Field et al. (1982) and Clarke (1993) using PRIMER software (Plymouth Marine Laboratory, UK). Briefly, abundance data were double-square-root transformed, the Bray-Curtis measure was used to generate a similarity matrix and the technique of non-metric multidimensional scaling (MDS) was applied to the matrix. ANOSIM tests were done on each similarity matrix to examine differences among sites, locations and depths (see Clarke 1993). The program RELATE in the PRIMER package was used to calculate the rank correlation between each pair of the 4 similarity matrices to determine whether results from each combination of mesh-size and level of identification were significantly correlated (see Clarke et al. 1993).
Analyses of populations. Mesh-size: Analysis of variance (ANOVA) was used to determine whether spatial patterns of abundance of families varied between mesh-sizes. Analyses were not done for particular species because few speries within each family were abundant enough for ANOVA and these were significantly correlated with family abundances (see below). Similarly, only the number of families per sample and not the number of species was analysed using ANOVA because these 2 variates were significantly correlated $(\mathrm{r}=0.98, \mathrm{df}=70 \mathrm{p}<0.01)$ and would show the same result. The factors in each ANOVA were sieve mesh-size, depth of water, location and sites nested within each location. All except sites were fixed factors for the purposes of this investigation.

A significant interaction between mesh-size and any spatial factor (depth, location or site) in ANOVA indicated that mesh-size affected the interpretation of spatial patterns at a particular scale. For example, an interaction between mesh-size and locations indicated that mesh-size affected the interpretation of spatial patterns between locations. We were less interested in the significance of mesh-size as a main effect in ANOVA because this would merely indicate that differences in abundance of a similar magnitude occurred between $0.5 \mathrm{~mm}$ and $1 \mathrm{~mm}$ meshes over all levels of depths, locations and sites but did not affect the description of spatial patterns.

Since the distribution of macrofauna is often aggregated (Elliot 1977, Stephenson \& Cook 1977, Downing 1979), all abundance data were transformed to $\log _{10}(x+1)$ which, in most cases, satisfied the assumption of homogeneous error variances (Cochran's test, $p$ $>0.05$ ). Data on the numbers of taxa were only transformed if necessary to achieve homogeneity of variances. If variances were homogeneous at $0.05>\mathrm{p}>$ 0.01 , $\alpha$ was set at 0.01 (Underwood 1981). Average data were used for the lost sample of molluscs. Post hoc pooling of non-significant factors (where $p>0.25$ ) followed the procedures in Winer et al. (1991) and was done to provide better tests of terms remaining in the ANOVA model. Student-Newman-Keuls (SNK) tests were used to differentiate means for significant main effects and interactions (Underwood 1981).

Taxonomic resolution: We wished to determine the contribution that individual species made to patterns revealed at the family level. Frequency distributions of the number of species per family were plotted for polychaetes, molluscs and crustaceans. Pearson correlation coefficients for the relationship between the abundance of individual families and species within that family were then calculated in 2 ways. First, we calculated correlations between abundance at the family level and the abundance of each species within the family to determine whether the degree of correlation 
was a simple function of the abundance of individual species within the family. Second, we asked how many of the species within a given family determined the patterns of abundance shown at the family level. For this we calculated correlations between the total abundance of selected families and the accumulated abundance of species in those families in their rank order of abundance (i.e. calculated the correlation between the single most abundant species and abundance of its family, then between the sum of the 2 most abundant species and abundance of their family, etc.). Data from both mesh-sizes were used in these analyses.

\section{RESULTS}

The total number of crustacean, polychaete and mollusc individuals collected was 21641 (14053 on $0.5 \mathrm{~mm}$ mesh, 7588 on $1 \mathrm{~mm}$ ) comprising 488 species ( 413 on $0.5 \mathrm{~mm}, 366$ on $1 \mathrm{~mm}$ ) and 146 families (126 on $0.5 \mathrm{~mm}$, 130 on $1 \mathrm{~mm}$ ). Crustaceans were the most abundant (total of 14510 individuals) and taxonomically rich (223 species, 63 families) group collected in all samples (0.5 and $1 \mathrm{~mm}$ meshes). Amphipods were the most abundant crustaceans (11356 individuals, 106 species, 28 families). Polychaetes (6008 individuals, 175 species, 35 families) and molluscs (1123 individuals, 90 species, 48 families) were also abundant. Other groups made up $<1 \%$ of the total abundance and are not considered here. Many of the species were undescribed, especially crustaceans. All specimens were identified to 'species' and to family except tanaidaceans (sub-order) and some isopods (sub-order Asellota, 2 species). These larger groups were included in MDS analyses of family data.

\section{Sorting time}

Significant mesh-size by location and depth by site within location interactions occurred for the time taken to sort each sample into major groups (Table 1a). At $\mathrm{PH}, 0.5 \mathrm{~mm}$ samples took about twice as long to sort as $1 \mathrm{~mm}$ samples, whereas at BP, $0.5 \mathrm{~mm}$ samples took about 4 times longer to sort than $1 \mathrm{~mm}$ samples (Fig. 2a). It took significantly longer to sort $0.5 \mathrm{~mm}$ samples from BP than $0.5 \mathrm{~mm}$ samples from $\mathrm{PH}$, but the time taken to sort the $1 \mathrm{~mm}$ samples did not differ between locations (SNK tests between locations for each mesh-size, Fig. 2a)

There was no significant difference in sorting times among depths at the PH sites (SNK tests among depths at each site, Fig. 2b), but sorting times varied among depths in different ways for sites at BP. At Site $3(\mathrm{BP})$, samples from 35 to 40 and 45 to $50 \mathrm{~m}$ took significantly

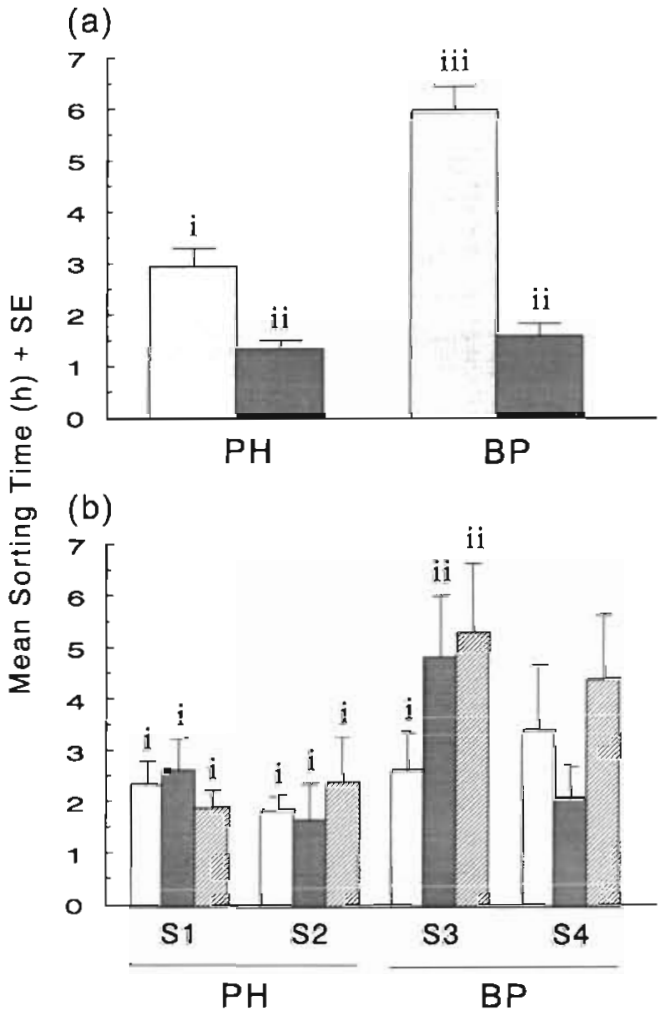

Fig. 2. (a) Time taken to sort samples sieved through a $0.5 \mathrm{~mm}$ mesh (light bars) or a $1 \mathrm{~mm}$ mesh (dark bars) (averaged over depths and sites, $\mathrm{n}=18$ ). PH: Providential Head; BP: Bass Point. Roman numerals: means differentiated by SNK tests between mesh-sizes for each location and vice versa. (b) Time taken to sort samples collected from 25 to $30 \mathrm{~m}$ (light bars), 35 to $40 \mathrm{~m}$ (dark bars) and 45 to $50 \mathrm{~m}$ (hatched bars) at each site (S1: Site 1; S2: Site 2; S3: Site 3; S4: Site 4) (averaged over mesh-sizes, $n=6$ ). Roman numerals: means differentiated by SNK tests among depths at each site, except Site 4 where no logical conclusion could be drawn

longer to sort than samples from 25 to $30 \mathrm{~m}$ (SNK test among depths). At Site 4 (BP), no logical conclusion could be drawn from the SNK test among depths but variation with depth was obviously arranged differently to that at Site 3 (Fig. 2b).

Sorting time and the total abundance of macrofauna (polychaetes, molluscs and crustaceans combined) per sample were significantly correlated ( $\mathrm{r}=$ 0.62, $\mathrm{df}=70, \mathrm{p}<0.01$ ). Thus, the $0.5 \mathrm{~mm}$ samples probably took longer to sort because they contained more animals and/or sediment (pers. obs.) than the 1 mm samples.

\section{Assemblages of macrofauna}

Assemblages of macrofauna varied among depths and between locations for all combinations of taxo- 
Table 1. Summary of ANOVA results for selected variates. Total number of individuals is shown in parentheses for each family. Data were transformed to $\log _{10}(x+1)$ for all variates except sorting time and number of families. Variances were homogeneous at $p>0.05$ for all variates except the Syllidae and Maldanidae for which variances were homogeneous at $p>0.01$ (Cochran's test). Post hoc pooling was done at $p>0.25$; superscripted a on MS shows pooled terms. Superscripts on $F$ ratios indicate the denominator MS used: a pooled MS, ${ }^{b}$ Site $(L o C),{ }^{C} \mathrm{M} \times \mathrm{S}(\mathrm{L}),{ }^{d} \mathrm{D} \times \mathrm{S}(\mathrm{L}),{ }^{\mathrm{e}} \mathrm{M} \times \mathrm{D} \times \mathrm{S}(\mathrm{L})$, 'residual. Values of $F$ and $P$ are not shown where $p>0.25$ or where tests were not relevant due to significant higher-order interactions

\begin{tabular}{|c|c|c|c|c|c|c|c|c|c|c|}
\hline Source & $\mathrm{df}$ & MS & $F$ & $\mathrm{p}$ & MS & $F$ & $\mathrm{p}$ & MS & $F$ & $p$ \\
\hline & & \multicolumn{3}{|c|}{ (a) Sorting time } & \multicolumn{3}{|c|}{ (b) Corophiidae (3175) } & \multicolumn{3}{|c|}{ (c) Aoridae (1186) } \\
\hline Mesh-size & 1 & 158.27 & & & 3.4397 & $23.22^{\mathrm{d}}$ & $<0.001$ & 0.8304 & $2.94^{\mathrm{c}}$ & $>0.20$ \\
\hline Depth & 2 & 5.66 & & & 1.8058 & & & 2.2734 & & \\
\hline Location & 1 & 49.58 & & & 0.9877 & & & 0.6957 & & \\
\hline Site $(\text { Loc })^{b}$ & 2 & 4.47 & & & 0.6794 & $4.59^{\mathrm{a}}$ & $<0.05$ & 0.7112 & & \\
\hline$M \times D$ & 2 & 2.36 & & & $0.0335^{\circ}$ & & & 0.1538 & & \\
\hline$M \times L$ & 1 & 35.07 & $24.81^{\mathrm{d}}$ & $<0.001$ & $0.2097^{a t}$ & & & 0.3487 & & \\
\hline$M \times S(L)^{c}$ & 2 & $0.65^{\mathrm{a}}$ & & & $0.0035^{a}$ & & & 0.2824 & $2.08^{d}$ & $>0.10$ \\
\hline $\mathrm{D} \times \mathrm{L}$ & 2 & 5.36 & & & 0.6226 & $4.20^{\mathrm{a}}$ & $<0.05$ & 0.3388 & & \\
\hline $\mathrm{D} \times \mathrm{S}(\mathrm{L})^{\mathrm{d}}$ & 4 & 5.54 & $3.92^{\mathrm{d}}$ & $<0.01$ & $0.1578^{a}$ & & & 1.5673 & $11.52^{\circ}$ & $<0.001$ \\
\hline $\mathrm{M} \times \mathrm{D} \times \mathrm{L}$ & 2 & 1.76 & & & $0.0200^{a}$ & & & $0.0711^{a}$ & & \\
\hline$M \times D \times S(L)^{e}$ & 4 & 2.68 & $1.89^{a}$ & $>0.10$ & $0.2084^{\mathrm{a}}$ & & & $0.0824^{a}$ & & \\
\hline \multirow[t]{2}{*}{ Residual $^{1}$} & 48 & $1.45^{\mathrm{a}}$ & & & $0.1563^{a}$ & & & $0.1425^{\mathrm{a}}$ & & \\
\hline & & \multicolumn{3}{|c|}{ (d) Apseudomorpha (1083) } & \multicolumn{3}{|c|}{ (e) Tanaidomorpha (731) } & \multicolumn{3}{|c|}{ (f) Phoxocephalidae (433) } \\
\hline Mesh-size & 1 & 0.4794 & & & 0.3188 & & & 0.8824 & $19.54^{\mathrm{d}}$ & $<0.001$ \\
\hline Depth & 2 & 5.7809 & & & 3.2913 & & & 1.1119 & $24.58^{d}$ & $<0.001$ \\
\hline Location & 1 & 8.8922 & $48.41^{\mathrm{b}}$ & $<0.05$ & 3.8789 & & & 0.4036 & $4.33^{b}$ & $>0.10$ \\
\hline Site $(\text { Loc })^{b}$ & 2 & 0.1837 & & & 0.9153 & & & 0.0933 & $2.06^{\mathrm{a}}$ & $>0.10$ \\
\hline$M \times D$ & 2 & 0.3308 & $3.35^{\mathrm{a}}$ & $<0.05$ & 0.2718 & & & $0.0380^{a}$ & & \\
\hline$M \times L$ & 1 & $0.0104^{\mathrm{d}}$ & & & 0.4186 & $4.11^{\mathrm{a}}$ & $<0.05$ & $0.0032^{\mathrm{a}}$ & & \\
\hline$M \times S(L)^{c}$ & 2 & $0.0275^{a}$ & & & $0.0025^{\mathrm{a}}$ & & & $0.0567^{a}$ & & \\
\hline $\mathrm{D} \times \mathrm{L}$ & 2 & 0.3380 & & & 0.8453 & & & $0.0270^{\mathrm{a}}$ & & \\
\hline$D \times S(L)^{d}$ & 4 & 0.5870 & $5.94^{\mathrm{d}}$ & $<0.001$ & 0.9696 & $9.51^{\mathrm{d}}$ & $<0.001$ & $0.0301^{\mathrm{a}}$ & & \\
\hline$M \times D \times L$ & 2 & $0.0039^{a}$ & & & 0.0762 & & & $0.0127^{\mathrm{a}}$ & & \\
\hline $\mathrm{M} \times \mathrm{D} \times \mathrm{S}(\mathrm{L})^{\mathrm{e}}$ & 4 & $0.0881^{\circ}$ & & & 0.1758 & $1.72^{\mathrm{a}}$ & $>0.10$ & $0.0128^{a}$ & & \\
\hline \multirow[t]{2}{*}{ Residual $^{\prime}$} & 48 & $0.1085^{a}$ & & & $0.1061^{\mathrm{e}}$ & & & $0.0520^{\mathrm{a}}$ & & \\
\hline & & \multicolumn{3}{|c|}{ (g) Syllidae (1767) } & \multicolumn{3}{|c|}{ (h) Spionidae (991) } & \multicolumn{3}{|c|}{ (i) Maldanidae (801) } \\
\hline Mesh-size & 1 & 2.1665 & & & 3.5836 & $55.15^{\mathrm{d}}$ & $<0.001$ & 0.4149 & $2.09^{d}$ & $>0.10$ \\
\hline Depth & 2 & 1.7321 & & & 1.8325 & & & 1.0364 & & \\
\hline Location & 1 & 5.6402 & $8.40^{b}$ & $>0.10$ & 0.1507 & $3.84^{\mathrm{b}}$ & $>0.10$ & 0.4158 & $5.26^{b}$ & $>0.10$ \\
\hline Site $(\text { Loc })^{b}$ & 2 & 0.6714 & & & 0.0392 & & & 0.0791 & & \\
\hline$M \times D$ & 2 & 0.0325 & & & 0.7812 & $6.29^{e}$ & $>0.05$ & 0.4367 & $2.20^{\mathrm{c}}$ & $>0.10$ \\
\hline $\mathrm{M} \times \mathrm{L}$ & 1 & 0.0291 & & & 0.0648 & & & 0.2023 & & \\
\hline$M \times S(L)^{c}$ & 2 & 0.5076 & $5.58^{\prime}$ & $<0.01$ & $0.0856^{\mathrm{a}}$ & & & $0.1516^{\mathrm{d}}$ & & \\
\hline$D \times L$ & 2 & 2.6756 & $7.45^{d}$ & $<0.05$ & 0.9202 & $2.86^{\mathrm{d}}$ & $>0.10$ & 1.5803 & & \\
\hline $\mathrm{D} \times \mathrm{S}(\mathrm{L})^{\mathrm{d}}$ & 4 & 0.3592 & $3.95^{\prime}$ & $<0.01$ & 0.3212 & $4.94^{\mathrm{a}}$ & $<0.01$ & 1.6533 & $8.32^{\circ}$ & $<0.001$ \\
\hline$M \times D \times L$ & 2 & 0.0818 & & & 0.0204 & & & 0.2930 & $1.47^{\circ}$ & $>0.20$ \\
\hline $\mathrm{M} \times \mathrm{D} \times \mathrm{S}(\mathrm{L})^{\mathrm{e}}$ & 4 & 0.2853 & $3.14^{i}$ & $<0.05$ & 0.1241 & $1.91^{\mathrm{d}}$ & $>0.10$ & $0.0670^{a}$ & & \\
\hline \multirow[t]{2}{*}{ Residual $^{i}$} & 48 & 0.0909 & & & $0.0641^{a}$ & & & $0.2118^{\mathrm{a}}$ & & \\
\hline & & \multicolumn{3}{|c|}{ (j) Sabellidae (548) } & \multicolumn{3}{|c|}{ (k) Nuculanidae (109) } & \multicolumn{3}{|c|}{ (l) No. of families } \\
\hline Mesh-size & 1 & 0.0101 & & & 0.0655 & & & 1160.0 & $24.37^{\mathrm{a}}$ & $<0.001$ \\
\hline Depth & 2 & 3.7388 & & & 2.5826 & & & 1279.6 & & \\
\hline Location & 1 & 0.0264 & $0.08^{b}$ & $>0.80$ & 0.0024 & & & 4186.1 & $17.70^{\mathrm{b}}$ & $>0.05$ \\
\hline Site $(\operatorname{Loc})^{b}$ & 2 & 0.3333 & & & 0.0858 & $2.20^{\mathrm{a}}$ & $>0.10$ & 236.6 & & \\
\hline$M \times D$ & 2 & 0.3728 & & & 0.1351 & $3.47^{\mathrm{a}}$ & $<0.05$ & 126.5 & & \\
\hline$M \times L$ & 1 & 0.0437 & & & $0.0027^{\mathrm{a}}$ & & & 105.1 & $2.21^{\circ}$ & $>0.10$ \\
\hline$M \times S(L)^{c}$ & 2 & 0.1392 & & & $0.0081^{\mathrm{a}}$ & & & $13.68^{\mathrm{a}}$ & & \\
\hline $\mathrm{D} \times \mathrm{L}$ & 2 & 0.3339 & & & 0.0765 & $1.96^{\mathrm{a}}$ & $>0.10$ & 271.1 & & \\
\hline$D \times S(L)^{d}$ & 4 & 0.2510 & & & $0.0372^{\mathrm{a}}$ & & & 169.2 & $3.55^{\mathrm{d}}$ & $<0.05$ \\
\hline $\mathrm{M} \times \mathrm{D} \times \mathrm{L}$ & 2 & 0.2659 & & & $0.0068^{\mathrm{a}}$ & & & 0.54 & & \\
\hline $\mathrm{M} \times \mathrm{D} \times \mathrm{S}(\mathrm{L})^{\mathrm{e}}$ & 4 & 0.3095 & $3.38^{f}$ & $<0.05$ & $0.0327^{a}$ & & & 84.31 & $1.77^{\mathrm{a}}$ & $>0.10$ \\
\hline Residual ${ }^{1}$ & 48 & 0.0916 & & & $0.0430^{\mathrm{a}}$ & & & $49.01^{\mathrm{a}}$ & & \\
\hline
\end{tabular}


(a) Species / $0.5 \mathrm{~mm}$ mesh

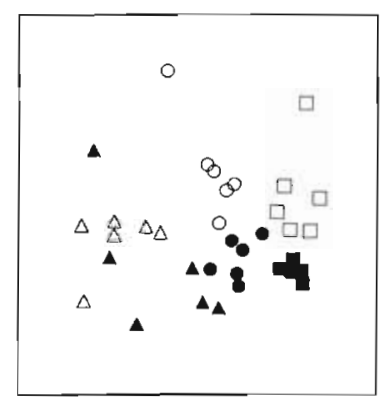

(c) Family $/ 0.5 \mathrm{~mm}$ mesh

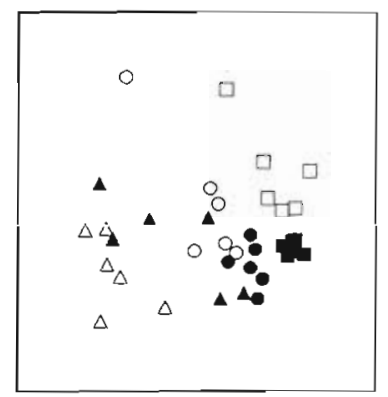

(b) Species $/ 1 \mathrm{~mm}$ mesh

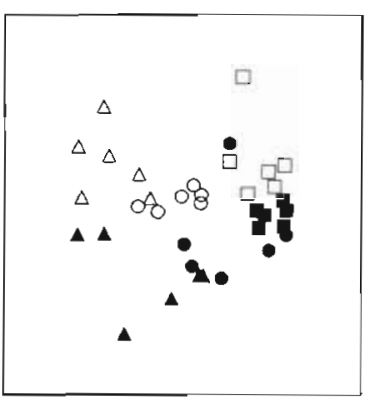

(d) Family $/ 1 \mathrm{~mm}$ mesh

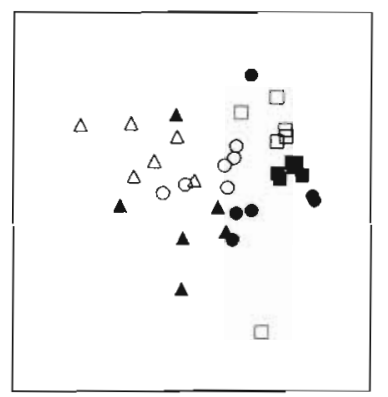

Fig. 3. Results of MDS analyses for all combinations of sieve mesh-size and taxonomic resolution. Each point represents 1 grab sample. $(\Delta, 0, \square)$ Samples taken at Providential Head $(\Delta, \bullet, \square)$ samples taken at Bass Point. $(\Delta, 4) 25$ to $30 \mathrm{~m} ;(0, \bullet)$ 35 to $40 \mathrm{~m}$; ( $\square, \square) 45$ to $50 \mathrm{~m}$ (as per Fig. 1). Stress values were (a) 0.13 , (b) 0.15 , (c) 0.14 and (d) 0.16

nomic resolution and mesh-size (Fig. 3). Despite the small-scale variation among replicate samples, the depth gradient was obvious, with 25 to $30 \mathrm{~m}$ samples grouping towards the left of each plot, 35 to $40 \mathrm{~m}$ samples in the middle, and 45 to $50 \mathrm{~m}$ samples towards the right. Differences among locations were also fairly clear with samples from $\mathrm{PH}$ towards the top of each plot and those from BP towards the bottom. By eye, spatial patterns were slightly less clear for family-level identification and $1 \mathrm{~mm}$ mesh than they were for species-level identification and $0.5 \mathrm{~mm}$ mesh.
ANOSIM currently allows up to 2 factors (see Clarke 1993) and therefore 2 analyses were done. First, we tested for differences between sites within each location over all depths using a nested, 2-factor ANOSIM (factors were locations and sites nested within locations; 9 samples per site, $n=3$ replicate grab samples from each of 3 depths). No significant differences were detected between sites within locations for any combination of mesh-size and taxonomic resolution (Table 2a). Because this was a powerful test (i.e. many possible permutations), we accepted the null hypothesis and inferred from the ANOSIM result that there were no differences between sites; we then pooled sites to test differences between locations and among depths in a separate ANOSIM (similar to post hoc pooling in ANOVA). This second test for differences among locations and depths was done using a 2-factor crossed ANOSIM (fartors were locations and depths; 6 samples for each combination of location and depth, $\mathrm{n}=3$ replicate grab samples from each of 2 sites within each location at each depth). Significant differences were detected between locations, among depths and among each pair of depths for each combination of mesh-size and taxonomic resolution (Table $2 \mathrm{~b}$ ). Thus, statistically similar spatial patterns were detected for each combination of taxonomic resolution and sieve mesh-size.

All pairs of the 4 combinations of taxonomic resolution and mesh-size were significantly correlated and thus showed similar results (RELATE results, Table 3 ). Despite this, rank correlation coefficients were higher $(\sim 0.9)$ for comparisons between species and family similarity matrices when mesh-size was the same (either 0.5 or $1 \mathrm{~mm}$ ) and lower $(\sim 0.6$ to 0.7$)$ for comparisons between 0.5 and $1 \mathrm{~mm}$ matrices regardless of the level of taxonomic resolution (Table 3). Rank correlations between the species $/ 0.5 \mathrm{~mm}$ similarity matrix and each of the other 3 matrices suggested that family $/ 0.5 \mathrm{~mm}$ was the next best combination (results were very similar to those for species $/ 0.5 \mathrm{~mm}$ ), with species $/ 1 \mathrm{~mm}$ and family/1 mm being worse combinations (Table 3). Thus more information may be lost by using a $1 \mathrm{~mm}$ instead of a $0.5 \mathrm{~mm}$ mesh than by using

Table 2. Significance levels ( $p$ ) for ANOSIM results. Separate 2-way analyses were done for (a) sites nested within locations and (b) crossed locations and depths (location, depth and pairwise depth below) for each combination of mesh-size and taxonomic resolution. A random sample of 20000 permutations from all possible permutations was used for each test. Results for each of the 3 pairwise tests between different depths were the same for each pair of depths for each combination of mesh-size and taxonomic resolution

\begin{tabular}{|c|c|c|c|c|}
\hline Possible permutations: & $\begin{array}{l}\text { (a) Sites (Loc) } \\
5.910 \times 10^{8}\end{array}$ & $\begin{array}{l}\text { (b) Location } \\
9.861 \times 10^{7}\end{array}$ & $\begin{array}{c}\text { Depth } \\
8.173 \times 10^{12}\end{array}$ & $\begin{array}{l}\text { Parrwise depth } \\
2.134 \times 10^{5}\end{array}$ \\
\hline Species $/ 0.5 \mathrm{~mm}$ & $>0.45$ & $<0.001$ & $<0.001$ & each $p<0.001$ \\
\hline Species/1. mm & $>0.10$ & $<0.001$ & $<0.001$ & each $p<0.001$ \\
\hline Family $/ 0.5 \mathrm{~mm}$ & $>0.35$ & $<0.001$ & $<0.001$ & each $p<0.001$ \\
\hline Family/1 mm & $>0.10$ & $<0.001$ & $<0.001$ & each $p<0.001$ \\
\hline
\end{tabular}


identification to species rather than family, but each combination of mesh-size and taxonomic resolution was significantly correlated.

\section{Populations of macrofauna}

\section{Mesh-size}

Significant interactions involving mesh-size were detected for 5 of the 11 variates analysed (Table 1). Mesh-size affected the interpretation of spatial patterns at each scale examined for at least 1 variate, i.e. among depths (Table 1d, k), locations (Table 1e), sites within locations (Table $1 \mathrm{~g}$ ) and among depths at each site (Table $1 \mathrm{j}$ ).

The significant interactions between mesh-size and depth in analyses of apseudomorph tanaidaceans and nuculanid bivalves were caused by significant differences in abundance between $0.5 \mathrm{~mm}$ and $1 \mathrm{~mm}$ samples from 45 to $50 \mathrm{~m}$ (SNK tests between mesh-sizes at each depth, Fig. 4a). There were similar numbers of these taxa in $0.5 \mathrm{~mm}$ and $1 \mathrm{~mm}$ samples at the other depths. The mean abundance of these taxa at 45 to $50 \mathrm{~m}$ was underestimated by the $1 \mathrm{~mm}$ mesh (com-
Table 3. Spearman rank correlation coefficients from comparisons of similarity matrices for each piir of the combinations of mesh-size and taxonomic resolution. All correlations were significant at $p<0.001$ (REL ATE in PRIMER; permutation test using a random sample of 20000 permutations)

\begin{tabular}{|lccc|}
\hline & $\begin{array}{c}\text { Species/ } \\
0.5 \mathrm{~mm}\end{array}$ & $\begin{array}{c}\text { Family/ } \\
0.5 \mathrm{~mm}\end{array}$ & $\begin{array}{c}\text { Species/ } \\
1 \mathrm{~mm}\end{array}$ \\
\hline Family $/ 0.5 \mathrm{~mm}$ & 0.92 & - & - \\
Species $/ 1 \mathrm{~mm}$ & 0.69 & 0.65 & - \\
Family/1 mm & 0.61 & 0.58 & 0.90 \\
\hline
\end{tabular}

pared with the $0.5 \mathrm{~mm}$ mesh). This difference and the effect on the interpretation of spatial patterns was large for apseudomorphids but small for nuculanids (Fig. 4a).

A significant mesh-size by location interaction occurred for tanaidomorph tanaidaceans (Table 1e). There was no difference between mesh-sizes at PH but there were more tanaidomorphs in the $0.5 \mathrm{~mm}$ samples than in the $1 \mathrm{~mm}$ samples at BP (SNK tests between mesh-sizes for each location, Fig. 4 b). This difference was, however, very small and the interpretation of differences between locations was little affected. The
Fig. 4. (a) Mean abundance of apseudomorph tanaidaceans and nuculanid bivalves collected from 25 to $30 \mathrm{~m}$ (light bars), 35 to $40 \mathrm{~m}$ (dark bars) and 45 to $50 \mathrm{~m}$ (hatched bars) estimated from samples sieved using a 0.5 or $1 \mathrm{~mm}$ mesh (avoraged over locations and sites, $\mathrm{n}$ =12). Roman numerals: means differentiated by SNK tests among depths for each mesh-size and vice versa. (b) Mean abundance of tanaidomorph tanaidaceans at each location (PH: Providential Head, BP: Bass Point) estimated from samples sieved using a 0.5 or $1 \mathrm{~mm}$ mesh (averaged over depths and sites, $n=18$ ). Roman numerals on bars show means differentiated by SNK tests between locations for each mesh-size and vice versa. (c) Mean abundance of syllid polychaetes at each site (\$1: Site 1; $\$$ 2: Site 2; \$3: Site 3; S4: Site 4) estimated from samples sieved using a 0.5 or $1 \mathrm{~mm}$ mesh (averaged over depths, $\mathrm{n}=9$ ). Roman numerals: means differentiated by SNK tests among sites for the $1 \mathrm{~mm}$ mesh. No logical conclusion could be drawn from the SNK test on $0.5 \mathrm{~mm}$ means. (d) Magnitude of significant differences in the mean number of corophiid and phoxocephalid amphipods, spionid polychaetes and families of macrofauna collected from samples sieved using a $0.5 \mathrm{~mm}$ mesh (light bars) or a $1 \mathrm{~mm}$ mesh (dark bars) (averaged over depths, locations and sites, $n=36$ ) (a)

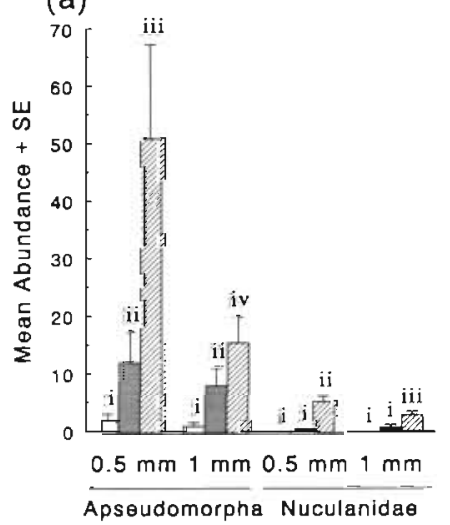

(c)

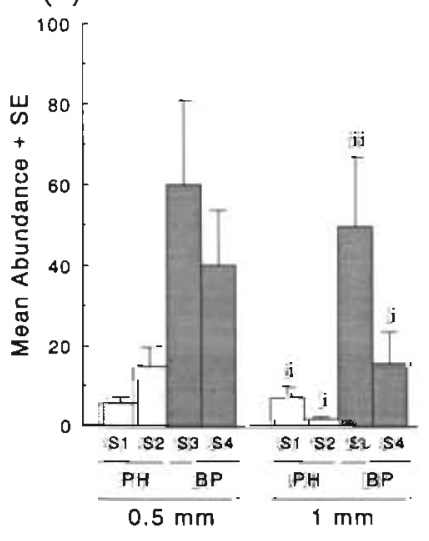

(b)

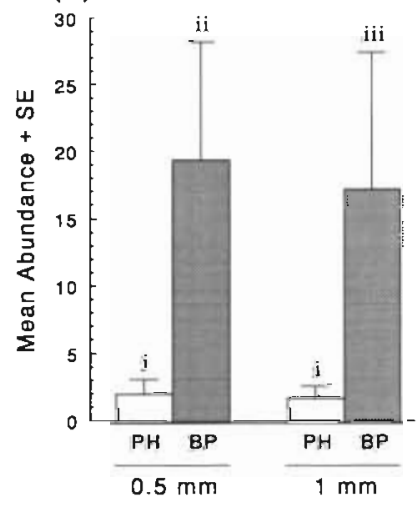

(d)

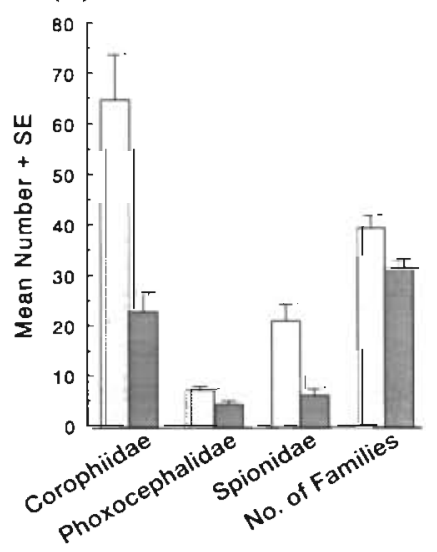



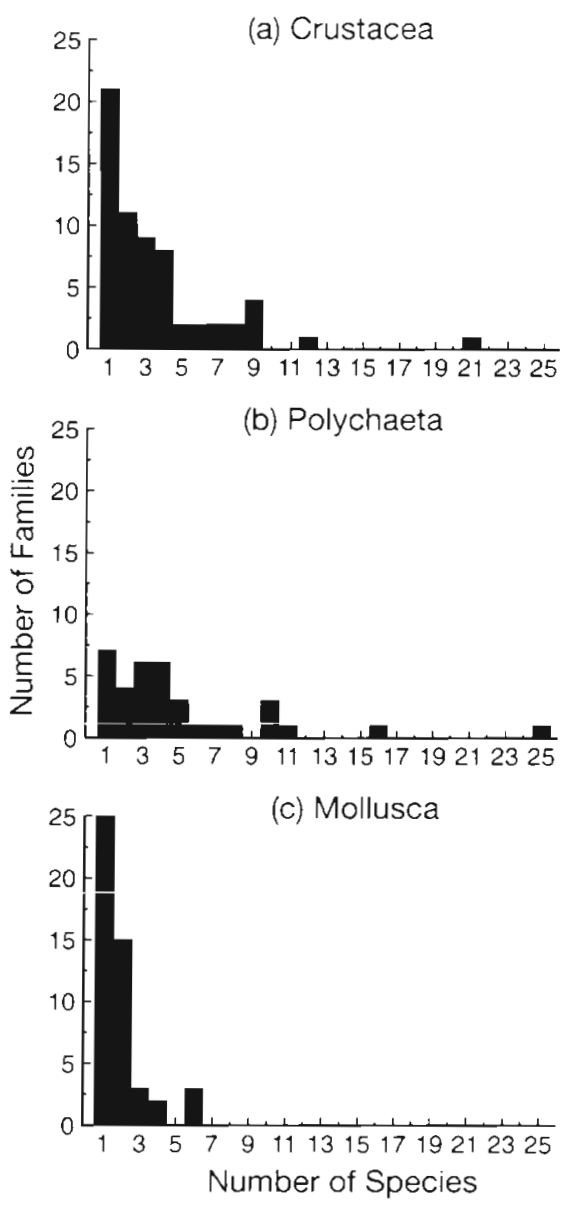

Fig. 5. Frequency distributions of the number of species in each family for (a) crustaceans, (b) polychaetes and (c) molluscs

abundance of these crustaceans was significantly greater at BP than at PH for both mesh-sizes (SNK tests between locations for each mesh-size, Fig. 4b).

Mesh-size affected interpretation of the distribution of syllids among sites (Table $1 \mathrm{~g}$ ). The interaction was caused by more syllids in the $0.5 \mathrm{~mm}$ samples than the $1 \mathrm{~mm}$ samples at Sites 2 and 4 but similar numbers at the other 2 sites (SNK tests between mesh-sizes for each site). For the $1 \mathrm{~mm}$ samples, syllids were most abundant at Site 3 and similarly abundant at the other sites (SNK test on $1 \mathrm{~mm}$ means, Fig. 4c). No logical conclusion could be drawn from the SNK test on the $0.5 \mathrm{~mm}$ means but the distribution among sites was obviously different to that obtained from the $1 \mathrm{~mm}$ samples.

A significant interaction among mesh-size, depth and site occurred for sabellid polychaetes (Table 1j). Patterns of distribution among depths varied between mesh-sizes at 3 of the 4 sites (SNK tests among depths for each combination of mesh-size and site, not illustrated).
Mesh-size did not affect the interpretation of spatial patterns for the other 6 families examined (i.e. there were no interactions involving mesh-size; Table $1 b, c$, f, h, i, l). Significantly more corophiid amphipods, phoxocephalid amphipods, spionid polychaetes and families were collected on the $0.5 \mathrm{~mm}$ mesh than on the $1 \mathrm{~mm}$ mesh at all depths and spatial scales (Table $1 b, f, h, 1, F i g .4 d$ ). This difference was greatest for corophiids and very small for phoxocephalids. These differences in abundance or numbers of families between mesh-sizes did not interact with any spatial factors (Table 1) and, therefore, had no effect on our interpretation of spatial patterns. No effects due to mesh-size occurred in analyses of aorid amphipods and maldanid polychaetes and again either mesh-size would have led to similar interpretations of spatial patterns.

\section{Taxonomic resolution}

There were usually fewer than 4 species of crustacean per family, although the Corophiidae (Amphipoda) had 21 species and the Gynodiastylidae (Cumacea) had 12 species (Fig. 5a). Many of the families with only 1 species were decapods and there were relatively few amphipod, isopod or cumacean families with more than 3 or 4 species.

There were often fewer than 5 species in each family of polychaetes (Fig. 5b). The largest number of species per family occurred in the Spionidae (25) and Syllidae (16). Most families of molluscs contained only 1 or 2 species (Fig. 5c). Analyses of the abundance of molluscs at the family level are therefore likely to reflect the distribution of the most abundant species. Usually, only 1 or 2 species made up more than $75 \%$ of the total abundance of molluscan families.

One species dominated the abundance (>50\%) of each of the speciose families Syllidae, Spionidae and Aoridae (Fig. 6a, b, c). The correlation between the abundance of these species and abundance at the family level was high $(r>0.80)$. In contrast, the Corophiidae had 3 species that dominated abundance but individually comprised $\leq 20 \%$ of the total abundance of the family (Fig. 6d). The abundance of these 3 species were the most correlated with abundance at the family level but these correlations were lower than those for the most abundant species in the Syllidae, Spionidae and Aoridae. Correlations between the abundance of rarer species and abundance at the family level were variable for the 4 families examined and were not a simple function of percent of total abundance within families.

Correlations of cumulative species abundances and abundance at the family level suggested that the number of species that dominated the spatial patterns 
(a) Syllidae - 16 species

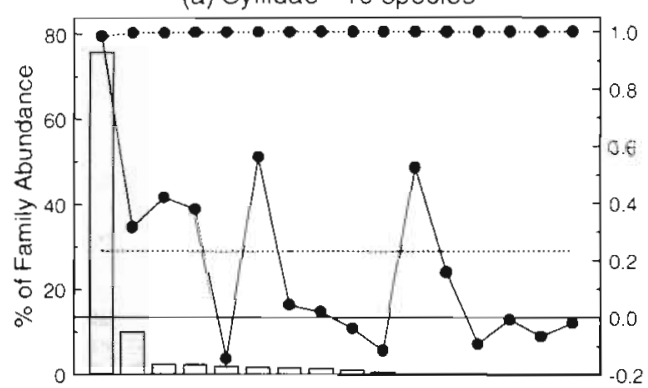

(c) Aoridae - 8 species

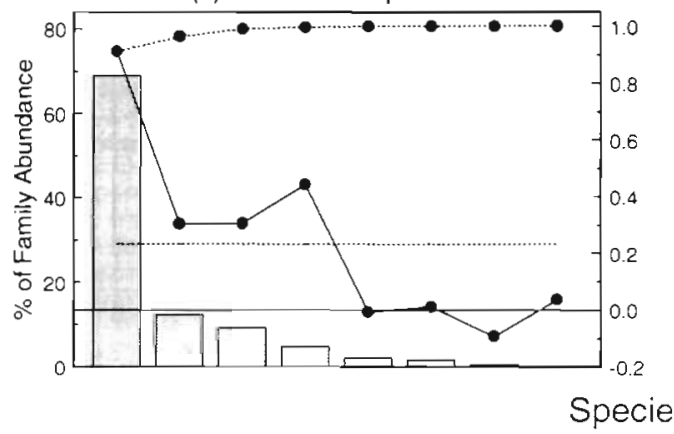

(b) Spionidae - 25 species

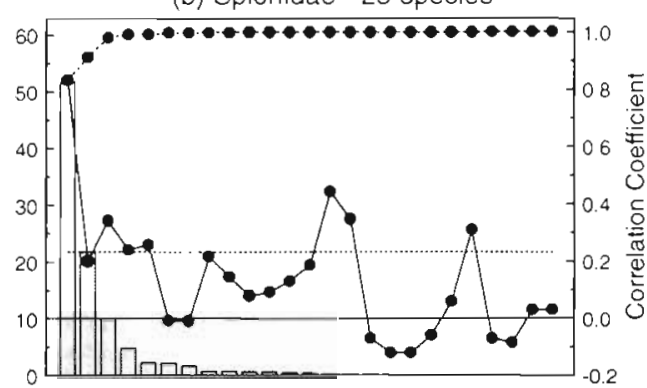

(d) Corophiidae - 21 species

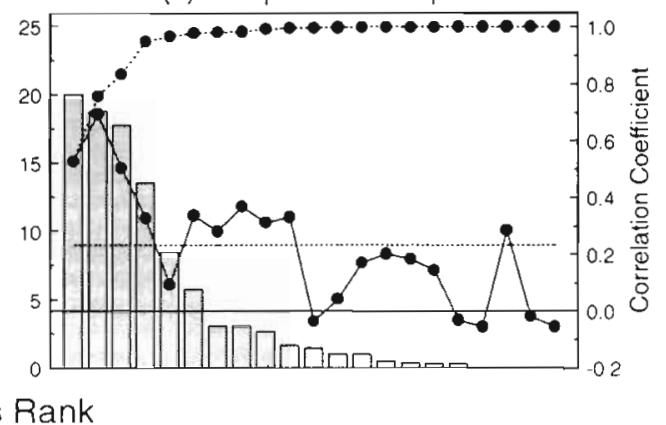

Fig. 6. Abundance (\% of family, bars) of each species in the families (a) Syllidae, (b) Spionidae, (c) Aoridae and (d) Corophiidae with the correlation of the abundance of each species with family-level abundance $(\bullet-\bullet)$ and the correlation of cumulative, ranked species abundances with family-level abundance $(\bullet . . . \bullet \cdot$ ). Dashed horizontal line: critical correlation value ( $p=0.05)$ for individual correlations

detected in family level analyses varied among families (Fig. 6). The most abundant species in the Syllidae and Aoridae dominated the spatial patterns for these families. The 3 most abundant species dominated spatial patterns for the Spionidae and the 4 most abundant species dominated the spatial patterns detected at the family level for the Corophiidae.

\section{DISCUSSION}

This study showed that the time taken to sort samples of macrofauna that had been sieved through a $0.5 \mathrm{~mm}$ mesh was much greater than for samples sieved through a $1 \mathrm{~mm}$ mesh. Further, the magnitude of this difference varied between locations. The time taken to sort samples to phyla also varied across depths and sites regardless of mesh-size. Some of the extra time required to sort $0.5 \mathrm{~mm}$ samples was due to the use of a binocular microscope to scan these samples after sorting. Binocular microscopes are, however, probably essential for sorting $0.5 \mathrm{~mm}$ samples (e.g. Hartley 1982). Samples sieved using a $0.5 \mathrm{~mm}$ mesh generally contained more macrofauna and sediment than those sieved using a $1 \mathrm{~mm}$ mesh. The greater number of animals is probably due to the additional juvenile forms collected using a $0.5 \mathrm{~mm}$ mesh
(R. Springthorpe, Australian Museum, Sydney, pers. comm.). Moreover, the relative abundance of juveniles may vary through time.

Juveniles are also difficult to identify and may greatly increase the total time taken to identify macrofauna. From this pilot study it was estimated that identification of macrofauna to species in the subsequent main study using approximately 600 samples would have taken about $2 \mathrm{yr}$ if the samples were sieved using a $0.5 \mathrm{~mm}$ mesh (A. Jones, Australian Museum, pers. comm.). In practice, these 600 samples were sieved using a $1 \mathrm{~mm}$ mesh and the macrofauna were identified to family in $8 \mathrm{mo}$. Thus, setting the sieve mesh-size at $1 \mathrm{~mm}$ rather than at $0.5 \mathrm{~mm}$ and identifying macrofauna only to family reduced the time of sorting and identification by twothirds.

Similar spatial patterns in natural assemblages of macrofauna were detected from samples sieved using a $1 \mathrm{~mm}$ mesh where macrofauna were identified only to family and samples sieved using a $0.5 \mathrm{~mm}$ mesh where macrofauna were identified to species. Studies of the effects of pollution on assemblages of macrofauna have also shown similar patterns in abundance at both the species and family levels of identification (Warwick 1988a, b, Ferraro \& Cole 1990, 1992, Gray et al. 1990, Warwick et al. 1990). The present study 
extends these results to assemblages of macrofauna probably unaffected by pollution.

Warwick $(1988 \mathrm{a}$, b) proposed that natural environmental variation or disturbances affect assemblages of macrofauna at the level of species whereas anthropogenic disturbances affect assemblages at higher taxonomic levels. This suggests that identification to species is required to describe natural spatial variation in assemblages of macrofauna. The present study showed, however, that patterns of spatial variation in natural assemblages of macrofauna were the same at both the taxonomic levels of family and species.

The interpretation of spatial patterns detected using univariate analyses differed between mesh-sizes for some families of macrofauna. For some families, differences were small and the interpretation of spatial patterns was little affected. Relatively large differences in spatial patterns between mesh-sizes were, however. apparent for other families. If a study focuses on specific populations or subsets of macrofauna, the choice of mesh-size may be more critical than for studies of assemblages. The benefits of pilot studies to determine the appropriate mesh-size(s) for investigations of particular taxa or groups of taxa are obvious.

The absolute abundance of some families was underestimated using a $1 \mathrm{~mm}$ mesh compared with a $0.5 \mathrm{~mm}$ mesh (e.g. the Corophiidae and Spionidae). This type of result led Bachelet (1990) to conclude that 0.1 to $0.2 \mathrm{~mm}$ meshes should be used for studies of the population dynamics of macrofauna. In our study, these differences in absolute abundance were similar over all levels of the spatial factors examined and did not affect the description of spatial patterns. Similarly, these differences will have no effect on environmental impact assessment or other management decisions as these are often concerned with comparing the fauna from several areas with a view to placing developments in the least 'sensitive' area.

The advantage of sieving samples through a $0.5 \mathrm{~mm}$ mesh and identifying them to species is that additional information may be provided for individual populations of small animals and possibly recruits. Information potentially gained by identification to species is very limited, however, if the species is not described and/or there is little information available on the life history and ecology of the species. This is the case with most marine macrofauna in Australia. What is gained in taxonomic certainty is eroded as the species cannot be put (with any confidence) into any more ecological context than if we assume all species within particular families have similar life histories, feeding modes or other characteristics.

The effect of the level of identification (either species or family) on interpretation depended on the number of species within each family and the distribution of abundance among species in the family. With only 1 species in a family, there can be no effect of taxonomic resolution on the interpretation of spatial variation. When there are 2 or more similarly abundant species within a family, analysis at the family level will reflect combined patterns of abundance. If there are 2 or more species within a family but 1 species is numerically dominant, analysis at the family level will be weighted by the pattern of the most abundant species. We recognize that such patterns will vary among assemblages and therefore recommend that graphical analyses like Fig. 6 be done as part of pilot studies.

It is important to note that in this study there were usually only 1 or 2 species within a family, especially for molluscs, and univariate analysis at the family level will reflect the spatial patterns of the abundant species. Some families contained many species (e.g. the Corophiidae. Syllidae and Spionidae). For the Syllidae and Aoridae, 1 species dominated the family abundance, and patterns of spatial variation found in univariate analyses at the family level reflected the patterns of spatial distribution of these abundant species. The 3 most abundant species in the Spionidae contributed to the spatial patterns detected in family-level analyses, but these contributions were weighted by abundance. The 4 most abundant species in the family Corophiidae made up a similar proportion of the total abundance of this family, and the spatial pattern of distribution found at the family level represented the distribution of these 4 species. There would be benefits in identifying the members of the Corophiidae to species if this family was the focus of further studies. Thus, there are clear benefits to be gained from pilot studies to determine the appropriate level of taxonomic resolution for investigations of particular groups of taxa. The generality of our results of few species per family needs to be assessed for more data sets covering a variety of geographical regions.

Abundances of the rarer species within families were not well correlated with abundances at the family level and spatial patterns detected using univariate analyses at the family level will not be representative of these species. These rarer species, however, are typically not analysed using univariate methods such as ANOVA because they usually are not abundant enough to satisfy the assumptions of these methods. Inferences drawn from analyses are likely to be unreliable due to the rarity of the animals. Since ecologists cannot interpret spatial patterns of these rarer species in commonly used sampling designs, identification to family instead of species merely results in loss of some data, not information (i.e. knowledge derived from data). This study showed that analyses of family-level abundances using ANOVA were little different to the analyses of abundant species that are typically done using this method. 
Multivariate methods that also consider the input of the less abundant taxa on the structure of assemblages (using appropriate data transformations and/or standardisations) may be the best method of incorporating abundances of rarer taxa into analyses.

Unlike most other studies, the present study considered the effects of mesh-size and taxonomic resolution simultaneously. In the MDS analyses, neither meshsize nor taxonomic resolution significantly affected the spatial patterns detected, and ANOSIM results were the same for each combination of these. The degree of correlation between each combination of taxonomic resolution and mesh-size shown by RELATE suggested that slightly more information was lost by using a coarser mesh than by using coarser taxonomic resolution, but all combinations were significantly correlated. In the univariate analyses, mesh-size interacted with depths and the 2 spatial scales examined for some variates. Taxonomic resolution affected the interpretation of spatial patterns for some species in speciose families. These results suggest that multivariate methods like MDS may be more robust to the use of larger mesh-sizes and higher levels of taxonomic resolution than univariate methods. Multivariate methods are quite sensitive to temporal and spatial variation in the structure of assemblages of macrofauna (e.g. Clarke 1993) and are useful tools for describing patterns of variation.

The results of this study have implications for largescale descriptive studies, the detection of environmental impacts, and monitoring programmes involving macrofauna. Large-scale studies of macrofauna require the processing of many samples which may be very time consuming and therefore expensive. Our results support the suggestions of authors such as Warwick (1993) who advocate the collection of more samples with savings through less time being initially spent on identification of fauna. Similarly, detecting environmental impacts increasingly involves the collection of many samples if studies are to be replicated properly (see Underwood 1991, 1992) and similar trade-offs between the number of samples taken and the coarseness of mesh-size and taxonomic resolution used for macrofauna are probably necessary. We do not advocate that the savings from using coarser taxonomic resolution or mesh-size be used to minimize the overall costs of a study. Instead, these resources should be used to obtain more information on biota to better answer environmental questions (based on some sort of cost-benefit analysis). If a choice is to be made between coarser taxonomic resolution or coarser mesh-size, it is important to consider that if samples are processed to a coarse taxonomic level and stored, further analyses could be done later at a finer taxonomic resolution if this extra expense is warranted (e.g. a particular species is shown later to be environmentally sensitive). It is not possible, however, to go back and redo sampling with a finer sieve mesh. Ideally, monitoring the effects of a development requires timely results in order to determine whether mitigative measures should be taken. It is of little value to have identification of macrofauna to species from samples sieved through a fine mesh taking many months to achieve if a lesser level of identification and a coarser mesh will enable an impact (of a predetermined size or larger) to be detected much sooner, thus allowing environmental managers to respond quickly.

Acknowledgements. This study was funded by Metromix Pty Ltd, and we thank the company and especially J. Hann for their support. Samples were collected with the assistance of Vic Blaslov and the crew of 'Winkles' P. Hawes helped to collect and sort the samples and drafted the map. G. Inglis, R. Warwick and 2 anonymous referees made comments that improved the manuscript. K. Clarke kindly supplied the PRIMER computer programs which were used for the multivariate analyses. Macrofauna were identified by I. Loch (molluscs), A. Murray (polychaetes) and R. Springthorpe (crustaceans) of the Australian Museum, Sydney.

\section{LITERATURE CITED}

Andrew, N. L., Mapstone, B. D. (1987). Sampling and the description of spatial pattern in marine ecology. Oceanogr mar. Biol. A. Rev. 25: 39-90

Bachelet, G. (1990). The choice of a sieving mesh size in the quantitative assessment of marine macrobenthos: a necessary compromise between aims and constraints. Mar environ. Res. 30: 21-35

Bishop, J. D. D., Hartley, J. P. (1986). A comparison of the fauna retained on $0.5 \mathrm{~mm}$ and $1 \mathrm{~mm}$ meshes from benthic samples taken in the Beatrice Oilfield, Moray Firth, Scotland. Proc. R. Soc. Edinb. 91B: 247-262

Clarke, K. R. (1993). Non-parametric multivariate analyses of changes in community structure. Aust. J. Ecol. 18: 117-143

Clarke, K. R., Warwick, R. M., Brown, B. E. (1993). An index showing breakdown of seriation, related to disturbance, in a coral-reef assemblage. Mar Ecol. Prog. Ser. 102: $153-160$

Dawson-Shepherd, A. R., Warwick, R. M., Clarke, K. R. (1992). An analysis of fish community responses to coral mining in the Maldives. Environ. Biol. Fish. 33: 367-380

Downing, J. A. (1979). Aggregation, transformation, and the design of benthos sampling programs. J. Fish. Res. Bd Can. 36: 1454-1463

Eleftheriou, A., Holme, N. A. (1984). Macrofauna techniques. In: Holme, N. A., Mcintyre, A. D. (eds.) Methods for the study of marine benthos. Blackwell, Oxford, p. 140-216

Elliot, J. M. (1977). Some methods for the statistical analysis of samples of benthic invertebrates. Freshwater Biol. Ass., Sci. Pub. No. 25

Ellis, D. (1985). Taxonomic sufficiency in pollution assessment. Mar. Pollut. Bull. 16: 459

Ferraro, S. P., Cole, F. A. (1990). Taxonomic level and sample size sufficient for assessing pollution impacts on the Southern California Bight macrobenthos. Mar. Ecol. Prog. Ser. 67: 251-262

Ferraro, S. P. Cole, F. A. (1992). Taxonomic level sufficient for 
assessing a moderate impact on macrobenthic communities in Puget Sound, Washington, USA. Can. J. Fish. Aquat. Sci. 49: 1184-1188

Field, J. G., Clarke, K. R., Warwick, R. M. (1982). A practical strategy for analysing multispecies distribution patterns. Mar. Ecol. Prog. Ser. 8: 37-52

Gray, J. S., Clarke, K. R., Warwick, R. M., Hobbs, G. (1990). Detection of initial effects of pollution on marine benthos: an example from the Ekofisk and Eldfisk oilfields, North Sea. Mar. Ecol. Prog. Ser. 66: 285-299

Green, R. H. (1979). Sampling design and statistical methods for environmental biologists. Wiley, Chichester

Hartley, J. P. (1982). Methods for monitoring offshore macrobenthos. Mar. Pollut. Bull. 13: 150-154

Heip, C., Warwick, R. M., Carr, M. R., Herman, P. M. J., Huys, R., Smol, N., Van Holsbeke, K. (1988). Analysis of community attributes of the benthic meiofauna of Frierfjord/Langesundfjord. Mar. Ecol. Prog. Ser. 46: 171-180

Herman, P. M. J., Heip, C. (1988). On the use of meiofauna in ecological monitoring: who needs taxonomy? Mar. Pollut Bull. 19: 665-668

Kennclly, S. J., Underwood, A. J. (1981). Underwater microscope sampling of a sublittoral kelp community. J. exp mar. Biol. Ecol. 76: 67-78

Kingston, P. F., Riddle, M. J. (1989). Cost effectiveness of benthic faunal monitoring. Mar. Pollut. Bull, 20: 490-496

Metromix Pty Ltd (1993). Sydney marine aggregate proposal Environmental impact statement. Metromix Pty Ltd, Sydney

Rees, H. L. (1984). A note on mesh selection and sampling efficiency in benthic studies. Mar. Pollut. Bull. 15: 225-229

Reish, D. J. (1959). A discussion of the importance of screen size in washing quantitative marine bottom samples. Ecology 40: 307-309

Roy, P. S. (1984). The geology and marine sediments on the south Sydney inner shelf, S.E. Australia. New South Wales Geological Survey Report, GS 1984/1158. Univ. Sydney, Sydney

This article was presented by A. J. Underwood (Senior Editorial Advisor), Sydney, Australia
Smith, S. D. A., Simpson, R. D. (1993). The effects of pollution on the holdfast macrofauna of the kelp Ecklonia radiata. discrimination at different taxonomic levels Mar. Ecol. Prog. Ser. 96: 199-208

Stephenson, W., Cook, S. D. (1977). Aggregation of sublittoral macrobenthos in Moreton Bay, Queensland. Aust. J. Ecol. 2: $419-428$

Underwood, A. J. (1981). Techniques of analysis of variance in experimental marine biology and ecology. Oceanogr. mar. Biol. A. Rev. 19: 513-605

Underwood, A. J. (1991). Beyond BACI: experimental designs for detecting human environmental impacts on temporal variations in natural populations. Aust. J mar. Freshwat. Res. 42: 569-587

Underwood, A. J. (1992). Beyond BACI: the detection of environmental impacts on populations in the real, but variable, world. J. exp. mar. Biol. Ecol. 161: 145-178

Underwood, A. J. (1993). The mechanics of spatially replicated sampling programmes to detect environmental impacts in a variable world. Aust. J. Ecol. 18: 99-116

Warwick, R. M. (1988a). The level of taxonomic discrimination required to detect pollution effects on marine benthic communities. Mar. Pollut. Bull. 19: 259-268

Warwick, R. M. (1988b). Analysis of community attributes of the macrobenthos of Frierfjord/Langesundfjord at taxonomic levels higher than species. Mar. Ecol. Prog. Ser. 46 $167-170$

Warwick. R. M. (1993). Environmental impact studies on marine communities: pragmatical considerations. Aust. $\mathrm{J}$. Ecol. 18: 63-80

Warwick, R. M., Platt, H. M., Clarke, K. R., Agard, J., Gobin, $G$. (1990). Analysis of macrobenthic and meiobenthic community structure in relation to pollution and disturbance in Hamilton Harbour, Bermuda. J. exp. mar Biol. Ecol. 138: 119-142

Winer, B. J., Brown, D. R., Michels, K. M. (1991). Statistical principles in experimental design, 3rd edn. McGraw-Hill, New York

Manuscript first received: May 10, 1994

Revised version accepted: October 24, 1994 